\title{
ANALISIS PENERAPAN SISTEM MANAJEMEN PENDIDIKAN TINGGI UNTUK MEWUJUDKAN GOOD UNIVERSITY GOVERNANCE
}

\author{
Rispa Ngindana1, Langgeng Rachmatullah Putra ${ }^{2}$, Rinaldo Albertus ${ }^{3}$ \\ ${ }^{1}$ Fakultas Ilmu Administrasi, Universitas Brawijaya \\ korespondensi email: rispangindana@ub.ac.id \\ 2Fakultas Ilmu Administrasi, Universitas Islam Malang \\ email: langgengputra@unisma.ac.id \\ ${ }^{3}$ Fakultas Ilmu Administrasi, Universitas Brawijaya \\ email: crinaldoalbertus@gmail.com
}

\begin{abstract}
The implementation of higher education management system in public universities is not new anymore, but every challenge of innovation developed has always been a new problem for college maintainers. This research aims to analyse the implementation of education management system, and control system of educational system of education in higher education environment, especially State University and developing alternative model of coordination system in implementing higher education management system. The research methods used are qualitative research with case study approaches. The research location is determined based on purposive sample method. The results of the study showed that control system in implementing the management system of higher education in Brawijaya University involves several systems and actions as follows: 1) quality assurance system; 2) work properly; 3) Customer satisfaction guarantee; 4) Pay attention to and record stakeholders ' complaints; 5) management based on facts; 6) Continuous improvement.
\end{abstract}

Keyword: management system; educational management; university governance.

\begin{abstract}
ABSTRAK
Implementasi sistem manajemen pendidikan tinggi di lingkungan perguruan tinggi negeri bukan hal baru lagi, namun setiap tantangan dari inovasi yang dikembang selalu menjadi masalah baru bagi pengelola perguruan tinggi. Penelitian ini bertujuan untuk menganalisis pelaksanaan sistem manajemen pendidikan, dan sistem pengendalian dari sistem manjemen pendidikan di lingkungan pendidikan tinggi, khususnya universitas negeri dan mengembangkan alternatif model sistem koordinasi dalam penerapan sistem manajemen pendidikan tinggi. Metode penelitian yang digunakan adalah penelitian kualitatif dengan pendekatan studi kasus (case study). Lokasi penelitian ditentukan berdasarkan metode sampel purposive. Hasil penelitian menunjukkan sistem pengendalian dalam pelaksanaan sistem manajemen pendidikan tinggi di Universitas Brawijaya melibatkan beberapa sistem dan tindakan sebagi berikut:1) Sistem Penjaminan Mutu;2) Mengerjakan secara benar; 3) Jaminan Kepuasan Pelanggan; 4) Memperhatikan dan mencatat komplain stakeholders; 5) Manajemen berdasarkan fakta; 6) Perbaikan berkesinambungan.
\end{abstract}

Kata Kunci: sistem manajemen; manajemen pendidikan; tata kelola universitas.

\section{PENDAHULUAN}

Meningkatnya kebutuhan masyarakat akan kebutuhan pendidikan dalam hal ini pendidikan tinggi menjadi peluang tersendiri bagi perguruan tinggi, khususnya perguruan tinggi negeri (PTN) untuk berlomba-lomba menarik minat masyarakat terutama kalangan 
remaja agar memilih institusinya. Namun, persaingan PTN dalam memperebutkan pasar mahasiswa ini cukup berat (Elfian, Ariwibowo, \& Johan, 2018; Nulhaqim, Heryadi, Pancasilawan, \& Ferdryansyah, 2016). Penyelenggaraan administrasi pendidikan pada suatu institusi pendidikan seperti pendidikan tinggi yang ber-Badan Hukum Milik Negara (BHMN) sangat penting untuk dikajian secara mendalam. Status BHMN dalam praktiknya ternyata menimbulkan tantangan baru. Saat ini mulai bermunculan pemikiran baru tentang konsep-konsep penyelenggaraan perguruan tinggi dengan status BHMN secara ideal (Sutini, 2019; Rianti, 2011).

Idealnya penyelenggaraan perguruan tinggi perlu memperhatikan keterlibatan dan pemenuhan kebutuhan stakeholders dan lingkungan. Pelibatan ini sangat penting karena penyelenggaraan institusi perguruan tinggi negeri berdampak pada peran vital perguruan tinggi dalam mencetak dan menghasilkan calon pemimpin bangsa dan generasi penerus bangsa terbaik. Selain itu, lingkungan pendidikan tinggi juga perlu dipertimbangkan mengingat lingkungan pendidikan tinggi merupakan sebuah kelompok sosial yang responsif dan kritis dalam menanggapi permasalahan yang ada di sekitarnya (Arwildayanto, Suking, \& Sumar, 2018).

Dalam perkembangannya universitas didorong untuk melakukan perbaikan dalam untuk menumbuhkan masa depan organisasi melalui perencanaan strategis di bidang pendidikan, manajemen, penelitian dan pengabdian masyarakat. Selain itu, universitas sebagai lembaga pendidikan diharapkan dapat memberikan kontribusi pada pengembangan negara, baik melalui pengetahuan di bidang pemerintahan, lingkungan usaha dan publik (masyarakat) (Taufiq, 2018; Suryana, 2017; S, 2011).

Sebuah konsep yang menjadi solusi saat ini dalam manajemen pendidikan tinggi adalah implementasi good university governance. Good University Governance menjadi salah satu elemen penting dari reformasi perguruan tinggi negeri (PTN). Konsep good university governance merupakan turunan dari good corporate governance yang awalnya familiar diterapkan diranah swasta kemudian diadopsi oleh ranah publik (Larasati, Asnawi, \& Hafizrianda, 2018). Tujuan dari good university governance adalah untuk mengakomodasi internasionalisasi perguruan tinggi, meningkatkan daya saing, kualitas proses pembelajaran, kualitas manajemen internal, dan untuk mencapai kinerja yang diharapkan (Widjajanti \& Sugiyanto, 2015; Hénard \& Mitterle, 2010). Hingga kini masalah yang sering muncul dalam tatakelola universitas negeri antara lain birokrasi yang kaku, unit strategis yang kurang visioner, PNBP yang bermasalah, sentralisasi yang berlebihan, ketergantungan pada dana pemerintah, tata kelola keuangan yang kaku dan layanan yang kurang memuaskan. PTN sebagai pusat pengembangan ilmu dan teknologi diharapkan mampu meningkatkan peranannya dalam memajukan dan mempercepat pembangunan nasional (Sukirman \& Sari, 2012). Perguruan Tinggi diharapkan menjadi sebuah komunitas yang mampu melindungi dirinya dari pengaruh nilai-nilai lingkungan eksternal yang mungkin korup atay mengandung keburukan. Independensi diperlukan untuk mendukung terwujudnya inovasi atau perkembangan pemikiran dan ilmu pengetahuan (Anwar \& Pratolo, 2012). Penelitian ini disusun untuk menghasilkan gambaran untuk mengetahui benar akan konsep good university governance di salah satu perguruan tinggi BHMN. Harapan penulis atas tulisan ini adalah dapat mengedukasi masyarakat kampus agar lebih memahami dan berfikir kritis dalam merespon penyelenggaraan tata kelola pendidikan menuju penyelenggaraan perguruan tinggi yang lebih baik. Menurut Rabiah (2019), dengan pendidikan yang berkualitas, Indonesia dapat lebih terjamin dalam proses transmisi menuju demokrasi dan dapat membangun keunggulan kompetitif dalam persaingan global yang semakin intens. 


\section{TINJAUAN PUSTAKA}

\section{Manajemen Pendidikan Perguruan Tinggi}

Pengertian manajemen perguruan tinggi menurut Biro Perencanaan Depdikbud dalam Suharsaputra (2015) adalah perencanaan, pengorganisasian, kepemimpinan, pengendalian sumber daya pendidikan untuk mencapai tujuan pendidikan yang telah ditentukan yaitu mencerdaskan kehidupan bangsa dan mengembangkan manusia seutuhnya dengan cara beriman dan bertakwa kepada Tuhan Yang Maha Esa, berbudi pekerti yang luhur, memiliki pengetahuan dan keterampilan, kesehatan jasmani dan rohani, kepribadian yang baik, mandiri, serta betanggung jawab kepada masyarakat dan bangsa. Menurut Suharsaputra (2015) dalam bukunya "Manajemen Pendidikan Perguruan Tinggi" memberikan pandangan mengenai manajemen pendidikan perguruan tinggi sebagai proses pengelolaan yang mencakup perencanaan, pengorganisasian, pelaksanaan dan pengawasan dalam pendayagunaan sumber daya pendidikan guna melaksanakan peran dan tugas tridharma perguruan tinggi melalui strategi yang memperhatikan lingkungan internal dan eksternal dalam mencapai tujuan dengan suatu konteks kepemimpinan pendidikan. Kedua pengertian tersebut sudah sangat jelas menunjukkan bahwa manajemen pendidikan tinggi meliputi kegiatan perencanaan, pengorganisasian, kepemimpinan, pengawasan dan pengendalian sumber daya pendidikan.

\section{Good University Governance}

Sebelum kita membahas tentang good university governance, kita pahami dulu tentang government, governance dan university governance. Konsep "government" bermakna dominasi peranan pemerintah dalam penyelenggaran berbagai kekuasaannya yang sah. Sedangkan "governance" bermakna upaya menyampaikan kekuasaan dan mengelola sumber daya, serta mengelola permasalahan-permasalahan yang terjadi di masyarakat (Rahayu \& Wahab, 2013). Oleh karena itu, dari perbedaan makna tersebut dapat dipahami bahwa konsep governance adalah berkaitan dengan suatu proses yang menunjukan inklusifitas, bukan sebagai struktur organisasi maupun sebagai institusi. Perbedaan lainnya adalah dalam government subjek dan objeknya adalah "mereka", sedangkan governance subjek dan objeknya adalah "kita". Sehingga dapat disimpulkan bahwa government lebih kepada pemangku kepentingan/aktor, sedangkan governance lebih kepada sistem manajemen dan konsep dalam pengelolaan pemerintahan. Menurut Leach \& Percy-Smith (2001) dalam artikelnya Local Governance in Britain dijelaskan bahwa "kita" dalam Government adalah penerima pasif sedangkan "mereka" (pemerintah dan politisi) adalah yang mengatur, melakukan sesuatu, dan memberikan pelayanan. Sedangkan governance meleburkan perbedaan antara "mereka" (pemerintah dan politisi) dan "kita" (masyarakat yang diperintah) karena pemerintah, politisi dan masyarakat adalah bagian dalam governance process. Sehingga dapat kita pahami bahwa dalam konsep governance terdapat karakteristik democratic, equitable, transparent, rule of law, participatory and partnership.

Konsep governance dalam university governance merupakan suatu bentuk kebijakan-kebijakan dan proses sebuah universitas mengurus urusannya sendiri. Secara khusus bagaimana tatakelola tersebut, hal ini seperti diungkapkan oleh Pujiono \& Satyawan (2011) tata kelola dalam bentuk konstitusional dan proses dimana universitas mengatur urusannya sendiri. Tata kelola ini melibatkan kekuasaan atau kewenangan dalam mengalokasikan dan mengelola sumber daya. Hal ini melibatkan kebijakan dan prosedur untk pegambilan keputusan dan pengendalian dalam mencapai tatakelola orgaisasi yang efektif. Oleh karena itu, tata kelola ini mengacu kepada praktik yang mengharuskan adanya pengawasan, pengendalian, 
pengungkapan, transparansi, struktur universitas, delegasi, pengambilan keputusan, perencanaan, koherensi organisasi dan pengarahan.

Implementasi Good University Governance (tata kelola universitas yang baik) merupakan implementasi nilai prinsip-prinsip dari good corporate governance pada perguruan tinggi. Salah satu alasan pelaksanaan tata kelola Universitas yang baik akan mampu melindungi lembaga dari penipuan atau salah urus oleh pemegang hak otonomi dan mampu memberikan saran untuk perbaikan (Hénard \& Mitterle, 2010; Wardhani, Taufiq, Fuadah, Siddik, \& Awaluddin, 2019). Prinsip GUG adalah struktur tata kelola, otonomi, akuntabilitas, kepemimpinan, transparansi (Wardhani et al., 2019). Di Indonesia penerapan university governance diatur dalam Undang-Undang Republik Indonesia Nomor 20 Tahun 2003. Pasal 51 dalam Undang-Undang ini desbutkan bahwa pengelolaan pendidikan tinggi dilaksanakan berdasarkan prinsip akuntabilitas, responsivitas, dan transparansi. Selain itu terkait dengan efisiensi, efetifitas dan akuntabilitas pengelolaan pendidikan di atur dalam Peraturan Pemerintah Republik Indonesia Nomor 17 Tahun 2010, Undang Undang Republik Indonesia nomor 12 tahun 2012, Peraturan Pemerintah Republik Indonesia Nomor 4 dari 2014, Peraturan Menteri Pendidikan dan kebudayaan Republik Indonesia Nomor 49 tahun 2014 dan dalam statuta universitas masing-masing.

\section{METODE}

Jenis metode penelitian ini menggunakan metode penelitian dengan pendekatan penelitian studi kasus (case study research) dengan menggunakan desain penelitian deskriptif (descriptive). Lokasi penelitian dalam sebuah penelitian merupakan hal penting. Lokasi penelitian ini ditentukan berdasarkan metode purposive sampling. Sehingga diperoleh Perguruan Tinggi Negeri menuju PTN BH atau PTN BHMN yang masuk dalam 10 besar ranking nasional, terakreditas A oleh BAN PT, berlokasi di Jawa Timur, memiliki jumlah peminat terbanyak nasional, dan telah mengaplikasikan sistem manajemen pendidikan tinggi berbasis TIK dan sudah cukup lama ( $>10$ tahun). Berdasarkan pengkategorian tersebut, penelitian ini mencoba untuk melakukan penelitian di Universitas Brawijaya yang sudah mengimplementasikan Sistem Informasi Pendidikan Tinggi yang meliputi: SIMPEL, SIAM, SIUDA, SIREGI, SIADO, SIPP, SIDEA, SELMA, SIBEA. Data yang digunakan dalam penelitian ini berupa dokumentasi, arsip, dan aktifitas keseharian civitas akademika di Universitas Brawijaya.

\section{HASIL DAN PEMBAHASAN}

Penerapan sistem informasi dalam manajemen pendidikan tinggi merupakan langkah yang tepat untuk menanggapi isu saat ini sehingga dapat memaksimalkan peran perguruan tinggi dalam mewujudkan good university governance. Penerapan ini berdasarkan hasil penelitian menunjukkan hal yang positif baik bagi pemberi layanan maupun penerima layanan. Kemudahan-kemudahan yang diberikan oleh suatu sistem informasi manajemen mampu mendukung pimpinan dalam menghasilkan keputusan yang efektif dan efisien. Selain itu, mampu memotong alur birokrasi yang panjang di lingkungan perguruan tinggi.

Berikut ini adalah logika struktur sistem manajemen pendidikan di lingkungan Universitas Brawaijaya: 


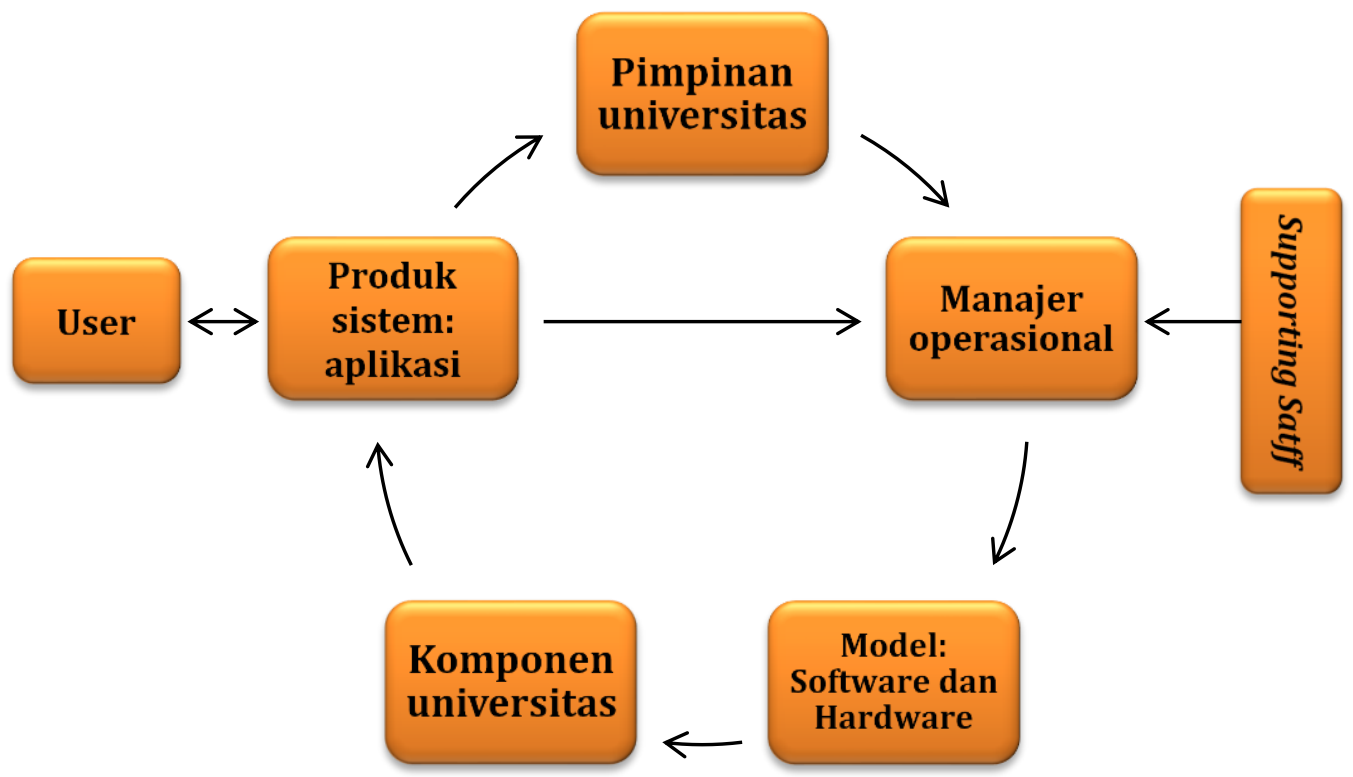

Gambar 1. Logika struktur sistem informasi manajemen pendidikan di lingkungan Universitas Brawijaya Sumber: data diolah penulis

Komponen sistem yang terapkan adalah terkait dengan pengelolaan laporan keuangan, administrasi akademik kemahasiswaan, administrasi akademik perkuliahan, evaluasi pembelajaran, neraca keuangan mahasiswa, administrasi wisuda, komunikasi sosial, pengelolaan layanan registrasi mahasiswa, pengelolaan administrasi dosen, pengelolaan kegiatan penelitian dan pengabdian, layanan beasiswa dan layanan calon mahasiswa baru. Komponen-komponen tersebut dikelola secara terpadu dan terintegrasi dalam Sistem Informasi Akademik Universitas Brawijaya (Siakad UB).

Semua sistem informasi yang dibuat tersebut dimaksudkan untuk mempermudah pelayanan kepada user di Universitas Brawijaya. Syarat penggunaan sistem informasi tersebut adalah harus memiliki username dan password. Ada beberapa sistem informasi yang tidak dapat diakses dengan mengggunakan email personal, hal ini dilakukan sebagai upaya untuk melindungi data-data penting dan bersifat internal.

Sistem pengendalian dalam pelaksanaan sistem manajemen Pendidikan Tinggi di Universitas Brawijaya melibatkan beberapa sistem dan tindakan sebagi berikut: 1) Sistem Penjaminan Mutu melalui audit internal mutu; 2) Mengerjakan secara benar (do it right); 3) Jaminan Kepuasan Pelanggan; 4) Memperhatikan dan mencatat komplain stakeholders; 5) Manajemen berdasarkan fakta; 6) Perbaikan berkesinambungan. Sistem pengendalian ini dilakukan secara online system maupun secara offline system.

Berdasarkan analisis SWOT yang dilakukan terhadap komponen sistem informasi manajemen yang diterapkan di Univeristas Brwaijaya diperoleh hal-hal sebagai berikut:

\section{Faktor Dominan}

Faktor dominan merupakan kekuatan dan peluang penerapan sistem manajemen pendidikan tinggi di Lingkungan Universitas Brawijaya mencakup:

a. Tersedianya media komunikasi dalam organisasi dan atar organisasi yang akurat, cepat dan ekonomis.

b. Kemudahan untuk mengakses segala informasi baik akademik, keuangan, kepegawaian dan sumber referensi.

c. Terjaminnya keterbukaan informasi yang dapat diakses dengan luas.

d. Memberikan peluang untuk membangun sumber-sumber informasi strategis dalam pelayanan pendidikan.

e. Membuka partisipasi stakeholder melalui e-complain 


\section{Faktor Penghambat}

Faktor penghambat merupakn kelamahan dan tantangan penerapan sistem informasi manajemen pendidikan tinggi di Universitas Brawijaya mencakup: a) Unstable politics; b) Komtenesi sumber daya manusia yang masih belum mendukung penggunaan sistem informasi berbasis teknologi tinggi; c) Sistem administras yang masih bersifat birokrasi kaku; d) Rendahnya produktivitas kerja; e) Belum maksimal tumbuhnya budaya mutu.

Budaya mutu ini masih lemah dalam penerapannya karena tidak semua pimpinan memahami budaya mutu ini. Penerapan budaya mutu ini sebenarnya dapat dikategorikan dalam implementasi good university governance. Unsur budaya mutu ini adalah sebagai berikut: 1) Informasi yang berkualitas harus digunakan sebagai dasar perbaikan; 2) Otoritas pimpinan dimaknai sebagai responsibility; 3) Penerapan reward dan punishment tergantung hasil yang dicapai; 4) Dasar kerjasama adalah kolaborasi dan sinergitas; 5)Kenyamanan dan keamanan karyawan (tenaga pendidikan dan tenaga kependidikan) harus terjamin dalam melaksanakan pekerjaannya; 6) Penerapan prinsip keadilan dan fairness.

Pemanfaatan faktor dominan, serta mengatasi faktor penghambat dapat dilakukan dengan pembinaan kemampuan profesional sumber daya manusia di Lingkungan Perguruan Tinggi, revitalisasi forum tenaga kependidikan dan forum dekan, peningkatan disiplin, dan peningkatan layanan bidang Tri Dharma.

a. Pembinaan Kemampuan Profesional sumber daya manusia di Lingkungan Perguruan Tinggi.

- Pelaksanaan pembinaan profesional dosen. Pimpinan di Lingkungan Perguruan Tinggi bisa menyusun program peningkatan kualitas pendidikan bagi dosen yang memiliki kualifikasi S2 agar mengikuti kuliah S3.

- Untuk menunjang profesionalitas tenaga kependidikan dan dosen yang bersifat khusus, maka Pimpinan di Lingkungan Perguruan Tinggi dapat mengikutsertakan tenaga kependidikan dan dosen pada acara seminar dan pelatihan yang diselenggarakan oleh institusi resmi pemerintah.

- Peningkatan profesionalisme dosen melalui sertifikasi dosen.

- Meningkatkan kesejahteraan tenaga kependidikan dan dosen diantaranya dengan memberikan insentif, tunjangan, dan penghargaan.

b. Peningkatan Disiplin dengan penerapan reward dan punishment.

c. Pembentukan Kelompok Diskusi Profesi bekerjasama dengan organisasi profesi.

d. Peningkatan kemampuan bahasa asing dan penguasaan aplikasi berbasis teknologi informasi dan komunikasi.

Upaya peningkatan peran dan kinerja pimpinan di Lingkungan Universitas Brawijaya dilakukan kegiatan pembinaan. Hal ini dilakukan untuk menjadikan Pimpinan di Lingkungan Universitas Brawijaya yang profesional. Kegiatan ini dilakukan oleh Senat, Satuan Pengendali Internal, Unit Penjaminan Mutu, dan Komisi Kode Etik. Adapun kegiatan pegembangan yang dilakukan adalah sebagai berikut:

1. Menjadikan pemimpin hebat dalam merespon educational management new paradigm berbasis teknologi informasi.

2. Menciptakan iklim kondusif sehingga memungkinkan pimpinan di lingkungan Universitas Brawijaya berdiskusi dengan kolega pimpinan di lingkungan universitas lainnya untuk memecahkan berbagai permasalahan yang dihadapi.

3. Memberi kesempatan seluas-luasnya kepada para pimpinan di lingkungan Universitas Brawijaya untuk melanjutkan ke jenjang pendidikan yang lebih tinggi guna menunjang karier dan meng-upgrade pengetahuannya. 
4. Mengadakaan pembinaan administrasi Pimpinan di Lingkungan Perguruan Tinggi (program tahunan, program kerja Pimpinan di Lingkungan Perguruan Tinggi dan kaur administrasi).

\section{KESIMPULAN}

Sistem informasi manajamen pendidikan adalah sistem informasi untuk menunjang proses layanan administrasi di Universitas Brawijaya secara terpadu dan terintegrasi. Bentuk implementasi sistem menajemn pendidikan tinggi di Universitas Brawijaya meliputi SIMPEL, SIAM, SIUDA, SIREGI, SIADO, SIPP, SIDEA, SELMA, SIBEA. Penerapan sistem / aplikasi tersebut tidak terlepas dari peran pimpinan dalam mewujudkan good university governance. Pemanfaatan faktor dominan dan mengatasi faktor penghambat dilakukan untuk mempertahankan dan memajukan siatem manajemen yang selama ini telah diterapkan di Universitas Brawijaya. Dampak posistif dari implementasi sistem manajemen pendidikan tinggi di Universitas Brawijaya antara lain:1) Efektivitas proses administrasi pendidikan;2) Tumbuhnya kepemimpinan Universitas Brawijaya yang transparan dan akuntabel; 3) Efektifitas pengelolaan sumber daya manusia; dan 4) Penerapan budaya mutu.

\section{DAFTAR RUJUKAN}

Anwar, M., \& Pratolo, S. (2012). Penerapan Model Tata Kelola Keuangan Perguruan Tinggi Yang Baik Untuk Mewujudkan Good University Governance (Studi Pada PTM se Indonesia). Universitas Muhammadiyah Yogyakarta.

Arwildayanto, Suking, A., \& Sumar, W. T. (2018). Analisis Kebijakan Pendidikan (Kajian Teoretis, Eksploratif, dan Aplikatif). (E. Kuswandi, Ed.) (1st ed.). Bandung: CV Cendekia Press.

Elfian, E., Ariwibowo, P., \& Johan, R. S. (2018). Peran Pendidikan Tinggi dalam Meningkatkan Minat Masyarakat untuk Produktivitas Pendidikan. Sosio E-Kons, 9(3), 200. https://doi.org/10.30998/sosioekons.v9i3.1870

Hénard, F., \& Mitterle, A. (2010). Governance and Quality Guidelinesin Higher Education (A Review of Governance Arrangements and Quality Assurance Guidelines). Paris: OECD/Directorate for Education.

Larasati, R., Asnawi, M., \& Hafizrianda, Y. (2018). Analisis Penerapan Good University Governance Pada Perguruan Tinggi Di Kota Jayapura. Journal of Applied Managerial Accounting, 2(2), 304-323. https://doi.org/10.30871/jama.v2i2.951

Leach, R., \& Percy-Smith, J. (2001). Local Governance in Britain (Contempora). Leeds: Palgrave.

Nulhaqim, S. A., Heryadi, D. H., Pancasilawan, R., \& Ferdryansyah, M. (2016). Peranan Perguruan Tinggi Dalam Meningkatkan Kualitas Pendidikan Di Indonesia Untuk Menghadapi Asean Community 2015 Studi Kasus: Universitas Indonesia, Universitas Padjadjaran, Institut Teknologi Bandung. Share : Social Work Journal, 6(2), 197-219. https://doi.org/10.24198/share.v6i2.13209

Pujiono, \& Satyawan, M. D. (2011). Menciptakan Mutu Perguruan Tinggi (Higher Educations) Berskala Internasional Melalui Strategi Penerapan Tata Kelola Universitas Yang Baik (Good University Governance). AKRUAL: Jurnal Akuntansi, 3(1), 58-68. https://doi.org/10.26740/jaj.v3n1.p59-69

Rabiah, S. (2019). Manajemen Pendidikan Tinggi Dalam Meningkatkan Mutu Pendidikan. Jurnal Sinar Manajemen, 6(1), 58-67. https://doi.org/10.31934/jsm.v6i1.551

Rahayu, S., \& Wahab, A. A. (2013). Pengaruh Penerapan Prinsip-Prinsip Good University Governance Terhadap Citra Serta Implikasinya Pada Keunggulan Bersaing 
Perguruan Tinggi Negeri Pasca Perubahan Status Menjadi Bhmn. Jurnal Administrasi Pendidikan, 17(1), 154-173. https://doi.org/10.17509/jap.v17i1.6441

Rianti. (2011). Kajian Yuridis Tentang Keberadaan Perguruan Tinggi Negeri Badan Hukum Milik Negara Dalam Undang-Undang Sistem Pendidikan Nasional. DiH: Jurnal Ilmu Hukum, 7(13), 1-10. https://doi.org/10.30996/dih.v7i13.252

S, U. C. (2011). Peran Pendidikan Tinggi Hukum Dalam Memenuhi Tuntutan Dunia Kerja. Jurnal Wawasan Yuridika (JWY), 24(01), 327-344. https://doi.org/10.25072/jwy.v24i1.21

Suharsaputra, U. (2015). Manajemen Pendidikan Perguruan Tinggi. Bandung: Refika Aditama.

Sukirman, \& Sari, M. P. (2012). Peran Internal Audit Dalam Upaya Mewujudkan Good University Governance Di UNNES. Jurnal Dinamika Akuntansi, 4(1), 64-71. https://doi.org/10.15294/jda.v4i1.1961

Suryana, S. (2017). Permasalahan Mutu Pendidikan Dalam Perspektif Pembangunan Pendidikan. Edukasi, 2(1). Retrieved from https://journal.unnes.ac.id/nju/index.php/edukasi/article/view/971

Sutini, L. (2019). Akibat Hukum PTN BH yang Tidak Memenuhi Evaluasi Kinerja. JuristDiction, 2(5), 1765-1786. https://doi.org/10.20473/jd.v2i5.15242

Taufiq, A. (2018). Paradigma Baru Pendidikan Tinggi dan Makna Kuliah Bagi Mahasiswa. MADANI Jurnal Politik Dan Sosial Kemasyarakatan, 10(1), 34-52. https://doi.org/10.1017/CB09781107415324.004

Wardhani, R. S., Taufiq, Fuadah, L. L., Siddik, S., \& Awaluddin, M. (2019). Good University Governance : Budgeting Participation. Asia-Pacific Management Accounting Journal, 14(1), 1-18. https://doi.org/10.24191/apmaj.v14i1.808

Widjajanti, K., \& Sugiyanto, E. K. (2015). Good University Governance Untuk Meningkatkan Excellent Service dan Kepercayaan Mahasiswa (Studi Kasus Fakultas Ekonomi Universitas Semarang). Jurnal Dinamika Sosial Budaya, 17(1), 69-81. https://doi.org/10.26623/jdsb.v17i1.504 